\title{
Cultivo hidropônico de cultivares de alface em soluções nutritivas organominerais otimizadas com a ferramenta SOLVER ${ }^{1}$
}

\author{
Antonio F. Monteiro Filho' ${ }^{1}$ Gilmara L. Pereira'2, Márcia R. Q. A. Azevedo³, \\ Josely D. Fernandes ${ }^{4} \&$ Carlos A. V. de Azevedo ${ }^{5}$ \\ ${ }^{1}$ Parte integrante da tese de doutorado do primeiro autor \\ ${ }^{2}$ UAEA/UFCG. Campina Grande, PB. E-mail: afernandesmf@gmail.com \\ ${ }^{3}$ CCAA/UEPB. Lagoa Seca, PB. E-mail: gilmaralimaagroecologia@gmail.com \\ ${ }^{4}$ CCAA/UEPB. Lagoa Seca, PB. E-mail: mzavedo@ccaa.uepb.edu.br \\ ${ }^{5}$ CCAA/UEPB. Lagoa Seca, PB. E-mail: joselysolo@yahoo.com.br (Autor correspondente) \\ ${ }^{6}$ UAEA/UFCG. Campina Grande, PB. E-mail: cazevedo@deag.ufcg.edu.br
}

Palavras-chave:

Lactuca sativa $\mathrm{L}$.

fertilizante

otimização

\begin{abstract}
R E S U M O
Objetivou-se, com este trabalho, avaliar o cultivo de cultivares de alface em sistema hidropônico tipo floating com soluções nutritivas otimizadas pela ferramenta SOLVER, do Microsoft Office Excel. O experimento foi conduzido no Centro de Ciências Agrárias e Ambientais da Universidade Estadual da Paraíba adotando-se o delineamento experimental inteiramente casualizado disposto em esquema fatorial 4 x 3, com três repetições. Os fatores foram 4 soluções nutritivas ( $\mathrm{S} 1=100 \%$ de solução mineral; $\mathrm{S} 2=90 \%$ de solução mineral + 10\% de solução orgânica; $\mathrm{S} 3=$ $84 \%$ de solução mineral + 16\% de solução orgânica e $S 4=78 \%$ de solução mineral + 22\% de solução orgânica) e 3 cultivares de alface (C1 - Crespa; C2 - Manteiga e C3 - Rubi). Avaliaram-se a altura da planta, o diâmetro caulinar, o número de folhas, o comprimento da raiz, a massa da matéria fresca e a massa da matéria seca da alface. As soluções organominerais promoveram uma resistência maior à variação do $\mathrm{pH}$ e substituíram parcialmente a solução mineral. As melhores médias biométricas e de produção ocorreram para as cultivares Crespa e Manteiga e para as soluções mineral, mineral $+10 \%$ de solução orgânica e mineral + $22 \%$ de solução orgânica.
\end{abstract}

Key words:

Lactuca sativa $\mathrm{L}$.

fertilizer

optimization

\section{Hydroponic cultivation of lettuce varieties under optimized organominerals nutrient solution with the SOLVER}

\begin{abstract}
A B S T R A C T
The study aimed to evaluate the cultivation of lettuce varieties in floating type hydroponic system with nutrient solutions optimized by the SOLVER tool of the Microsoft Office Excel. The experiment was conducted at the Center of Environmental and Agricultural Sciences Center of the Paraíba State University, adopting an entirely randomized experimental design arranged in factorial scheme $4 \times 3$, with three repetitions. The factors were 4 nutritient solutions $(\mathrm{S} 1=100 \%$ mineral solution; $\mathrm{S} 2=90 \%$ mineral solution $+10 \%$ organic solution; $\mathrm{S} 3=84 \%$ mineral solution $+16 \%$ organic solution and $\mathrm{S} 4=78 \%$ mineral solution $+22 \%$ organic solution) and 3 lettuce varieties $(\mathrm{C} 1-\mathrm{Crespa} ; \mathrm{C} 2$ - Monteiga and C3 - Ruby). The plant height, stem diameter, number of leaves, the length of the root, fresh matter weight and the dry matter weight of the lettuce were evaluated. The organominerals solutions promoted a greater resistance to variation of the $\mathrm{pH}$ and replaced partially the mineral solution. The best biometric and production means were observed for the Crespa and Monteiga varieties and for the mineral solution, mineral solution $+10 \%$ of organic solution and mineral solution $+22 \%$ of organic solution.
\end{abstract}

\section{INTRODUÇÃo}

Em quase toda sua totalidade, o Nordeste brasileiro está inserido nas fronteiras do que se denomina semiárido, caracterizado por índices pluviais baixos em algumas regiões e irregulares em outras (Silva et al., 2011). A região do brejo paraibano apresenta baixo índice de precipitação pluvial agravado pela falta de mananciais para armazenamento de água. A população local vive quase que exclusivamente da prática da agricultura familiar em que as hortaliças, em especial a alface, são as mais produzidas (Santos et al., 2011).
Uma alternativa para aumentar a renda dos produtores de hortaliças do brejo paraibano seria a produção hidropônica. Os agricultores que fazem uso do sistema hidropônico de produção obtêm maiores preços por seus produtos uma vez que neste método de produção há redução ou mesmo nenhuma utilização de agrotóxicos, além de ser um sistema que proporciona economia de água (Castellane \& Araújo, 1994).

Na região semiárida o sistema de hidroponia é, muitas vezes, inviabilizado pela carência de comercialização de fertilizantes solúveis, mesmo nos grandes centros da região nordeste, levando o produtor a importar esses insumos de 
outras regiões, o que aumenta significativamente seus custos. Uma prática que, sem dúvida nenhuma, pode oferecer redução dos custos de produção no sistema hidropônico, é a substituição ou diminuição do uso de fertilizantes minerais por fontes alternativas e mais econômicas como, por exemplo, a utilização de produtos orgânicos (soro de leite, melaço, esterco, urina de vaca etc.) disponíveis na propriedade na forma de biofertilizante caracterizando, assim, um sistema hidropônico orgânico ou organomineral. O interesse na utilização de resíduos orgânicos gerados no meio rural é justificado não apenas pelos aspectos de reciclagem de nutrientes no próprio meio e aumento no rendimento das culturas mas também pela diminuição dos custos com o preparo das soluções nutritivas. Neste sentido, a utilização de nutrientes a partir de biofertilizantes associada à técnica de cultivo hidropônico é mais uma alternativa para diminuir a extração das reservas naturais de nutrientes do planeta contribuindo para a prática do saneamento ambiental e da sustentabilidade da propriedade agrícola (Factor et al., 2008).

A utilização da hidroponia orgânica ou organomineral pode ser uma opção para atender às dificuldades de produção de pequenos e médios produtores de olerícolas que, muitas vezes, não dispõem de produção suficiente para atender à demanda do mercado consumidor durante todo o ano diminuindo, então, sua perspectiva de renda. Esta técnica não tenta competir com sistemas tradicionais de produção de olerícolas porém surge como alternativa de produção de alimentos de melhor qualidade nutricional e microbiológica potencializando sua aceitação por parte do consumidor.

Com o uso de solução organomineral a hidroponia se caracteriza como alternativa para a melhoria de vida do produtor da região semiárida uma vez que possibilita economia de água, diminuição dos teores de nitrato e maior economia de produção (Castellane \& Araújo, 1994; Martello et al., 2007).

A utilização de soluções orgânicas concentradas em sistemas hidropônicos já é alvo de pesquisa; Dias et al. (2009) recomendam a utilização de biofertilizantes com composição nutricional elevada visto que os nutrientes se mantêm na forma orgânica na solução nutritiva, não havendo mineralização por ausência de microrganismos neste ambiente de cultivo. A imobilização de nutrientes através de compostos orgânicos também deve ser considerada em virtude de influenciar na condutividade elétrica das soluções nutritivas.

Não há, praticamente, informações sobre formulações de biofertilizantes específicos para atender à necessidade nutricional de determinada cultura. A grande dificuldade de formular um biofertilizante com tais características está no cálculo para balancear cada nutriente uma vez que os ingredientes orgânicos possuem macro e micronutrientes em concentrações diferentes. O Solver do Microsoft Office Excel é uma ferramenta que poderá ser utilizada para solucionar tal problema por otimizar (minimizar ou maximizar) uma função de variáveis chamada função objetivo, sujeita a uma série de equações ou inequações lineares. Ante o exposto objetivouse, com este trabalho, avaliar o cultivo de três cultivares de alface em sistema hidropônico tipo Floating com diferentes soluções nutritivas, otimizadas por meio da ferramenta Solver do Microsoft Office Excel.

\section{Material e Métodos}

O experimento foi conduzido no Centro de Ciências Agrárias e Ambientais (CCAA/ UEPB) situado na cidade de Lagoa Seca, $\mathrm{PB}$, em ambiente protegido (casa de vegetação) no período de 24/04/2012 a 21/05/2012 utilizando-se o delineamento inteiramente casualizado disposto em esquema fatorial $4 \times 3$, com três repetições e quatro plantas por parcela. $\mathrm{O}$ primeiro fator se constituiu de 4 soluções nutritivas ( $\mathrm{S} 1=100 \%$ de solução mineral; S2 = 90\% de solução mineral $+10 \%$ de biofertilizante; S3 $=84 \%$ de solução mineral $+16 \%$ de biofertilizante e S $4=78 \%$ de solução mineral $+22 \%$ de biofertilizante) e o segundo fator por três (3) cultivares de alface (C1 - Crespa; C2 - Manteiga e C3 - Rubi). A solução mineral foi preparada conforme Hogland \& Snyder (1933).

O biofertilizante utilizado neste trabalho foi preparado no CCAA/UEPB cujos ingredientes necessários para o preparo de $100 \mathrm{~L}$ foram os seguintes: $0,159 \mathrm{~kg}$ de sangue bovino; $17,466 \mathrm{~kg}$ de esterco bovino; 9,952 kg de soro de leite e 72,423 L de água; após sua fermentação (aproximadamente quarenta dias) uma amostra do mesmo foi retirada e encaminhada ao Laboratório de Referência em Dessalinização - LABDES/UFCG para caracterização físico-química. A composição química percentual dos ingredientes utilizados na formulação das soluções nutritivas é apresentada na Tabela 1.

As soluções organominerais S2, S3 e S4, apesar de apresentarem níveis crescentes de biofertilizante, foram formuladas teoricamente com uma concentração nutricional dez vezes superior à recomendada por Hogland \& Snyder (1933); para isto, utilizou-se a ferramenta Solver do Microsoft Office Excel; todas as soluções foram preparadas para $100 \mathrm{~L}$.

A Tabela 2 apresenta a quantidade dos ingredientes e dos nutrientes utilizados na formulação de $100 \mathrm{~L}$ das soluções nutritivas e seus respectivos custos, como resultado da otimização realizada pelo Solver.

A ferramenta Solver do Microsoft Office Excel foi eficaz na formulação das soluções nutritivas corroborando com as informações de Fernandes et al. (2011) que formularam, com o auxílio do Solver, um biofertilizante capaz de atender às necessidades nutricionais da cultura do milho. As soluções apresentaram um custo de 0,$75 ; 4,07 ; 3,89$ e 3,70 R\$ $100 \mathrm{~L}^{-1}$, respectivamente, para solução mineral $(\mathrm{S} 1)$; solução mineral + 10\% de solução orgânica (S2); solução mineral + 16\% de solução orgânica (S3) e solução mineral $+22 \%$ de solução orgânica (S4). As soluções organominerais foram mais onerosas quando comparadas com a mineral, devido ao acréscimo dos fertilizantes: nitrato de potássio, nitrato de cálcio, fosfato monoamônio e sulfato de magnésio na sua composição para suplementar os baixos teores em nitrogênio, fósforo, potássio e magnésio dos ingredientes orgânicos. Apesar das soluções organominerais apresentarem concentração nutricional dez vezes superior à mineral os volumes das soluções estoque requeridos para se preparar $1000 \mathrm{~mL}$ de solução nutritiva, foram: 7,0; 8,0; 8,0 e 6,0 mL da S1, S2, S3 e S4, respectivamente. Esses volumes foram necessários para se obter uma condutividade

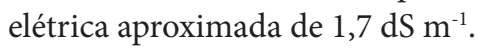


Tabela 1. Composição química percentual dos ingredientes utilizados para formulação das soluções nutritivas

\begin{tabular}{|c|c|c|c|c|c|c|c|c|c|c|c|c|c|c|c|c|c|}
\hline \multirow[b]{2}{*}{ Nutrientes } & \multicolumn{16}{|c|}{ Ingredientes utilizados para formulação das soluções nutritivas } & \multirow{2}{*}{$\begin{array}{c}\text { Solução de Hoagland } \\
\text { \& Snyder (1933) } \\
\text { kg } 100 \mathrm{~L}^{-1}\end{array}$} \\
\hline & $A^{(1)}$ & B & $\mathbf{C}^{(1)}$ & D & E & $\mathbf{F}$ & G & H & I & J & K & $\mathbf{L}$ & M & $\mathbf{N}$ & 0 & $\mathbf{P}$ & \\
\hline $\mathrm{N}$ & 0,46 & 0,17 & 0,12 & 0,00 & 14,00 & 11,80 & 11,50 & 0,00 & 0,0 & 0,00 & 0,00 & 0,00 & 0,00 & 0,00 & 0,00 & 0,00 & $2,10 \times 10^{-2}$ \\
\hline $\mathrm{P}_{2} \mathrm{O}_{5}$ & 0,08 & 0,15 & 0,05 & 0,00 & 0,00 & 0,00 & 60,00 & 22,80 & 0,0 & 0,00 & 0,00 & 0,00 & 0,00 & 0,00 & 0,00 & 0,00 & $3,00 \times 10^{-3}$ \\
\hline $\mathrm{K}_{2} \mathrm{O}$ & 2,38 & 0,1 & 0,08 & 49,80 & 47,00 & 0,00 & 0,00 & 28,70 & 60,0 & 0,00 & 0,00 & 0,00 & 0,00 & 0,00 & 0,00 & 0,00 & $2,30 \times 10^{-2}$ \\
\hline $\mathrm{Ca}$ & 0,82 & 0,13 & 0,06 & 0,00 & 0,00 & 17,00 & 0,00 & 0,00 & 0,0 & 0,00 & 0,00 & 0,00 & 0,00 & 0,00 & 0,00 & 0,00 & $2,00 \times 10^{-2}$ \\
\hline $\mathrm{Mg}$ & 0,35 & 0,02 & 0,13 & 0,00 & 0,00 & 0,00 & 0,00 & 0,00 & 0,0 & 0,00 & 0,00 & 0,00 & 10,00 & 0,00 & 0,00 & 0,00 & $4,80 \times 10^{-3}$ \\
\hline S & 0,35 & 0,457 & 1,04 & 0,00 & 0,00 & 0,00 & 0,00 & 0,00 & 0,0 & 12,00 & 11,00 & 21,00 & 13,00 & 0,00 & 0,00 & 0,00 & $10^{-3}$ \\
\hline B & 0,00 & 0,00 & 0,00 & 0,00 & 0,00 & 0,00 & 0,00 & 0,00 & 0,0 & 0,00 & 0,00 & 0,00 & 0,00 & 17,70 & 0,00 & 0,00 & $10^{-5}$ \\
\hline $\mathrm{Zn}$ & 0,03 & 0,00 & 0,00 & 0,00 & 0,00 & 0,00 & 0,00 & 0,00 & 47,0 & 0,00 & 35,50 & 0,00 & 0,00 & 0,00 & 0,00 & 0,00 & $1,20 \times 10^{-5}$ \\
\hline $\mathrm{Fe}$ & 0,00 & 0,00 & 0,02 & 0,00 & 0,00 & 0,00 & 0,00 & 0,00 & 0,0 & 0,00 & 0,00 & 0,00 & 0,00 & 0,00 & 0,00 & 34,43 & $5,00 \times 10^{-4}$ \\
\hline $\mathrm{Mn}$ & 0,00 & 0,00 & 0,00 & 0,00 & 0,00 & 0,00 & 0,00 & 0,00 & 0,0 & 0,00 & 0,00 & 28,00 & 0,00 & 0,00 & 0,00 & 0,00 & $9,80 \times 10^{-6}$ \\
\hline $\mathrm{Cu}$ & 0,00 & 0,00 & 0,00 & 0,00 & 0,00 & 0,00 & 0,00 & 0,00 & 0,0 & 25,00 & 0,00 & 0,00 & 0,00 & 0,00 & 0,00 & 0,00 & $1,12 \times 10^{-6}$ \\
\hline Custo $\mathrm{kg}^{-1}$ & 0,1 & 0,16 & 0,1 & 1,5 & 2,8 & 1,8 & 4,0 & 2,0 & 4,52 & 10,0 & 6,0 & 6,0 & 1,4 & 6,0 & 0,0 & 219,0 & \\
\hline
\end{tabular}

(1)Pereira et al. (2007); A - Melaço; B - Biofertiliante; C - Soro de leite; D - Cloreto de potássio (KCl); E - Nitrato de potássio $\left(\mathrm{KNO}_{3}\right)$; F - Nitrato de cálcio [Ca( $\left.\left.\mathrm{NO}_{3}\right)_{2}\right]$; G - Fosfato monoamôneo $\left(\mathrm{NH}_{4} \mathrm{H}_{2} \mathrm{PO}_{4}\right) ; \mathrm{H}$ - Fosfato de potássio $\left(\mathrm{KH}_{2} \mathrm{PO}_{4}\right) ; \mathrm{I}$ - Cloreto de potássio $(\mathrm{KCl}) ; \mathrm{J}$ - Sulfato de cobre $\left(\mathrm{CuSO}_{4}\right) ; \mathrm{K}$ - Sulfato de zinco $\left(\mathrm{ZnSO}_{4}\right) ; \mathrm{L}$ - Sulfato de manganês $\left(\mathrm{MnSO}_{4}\right) ; \mathrm{M}$ - Sulfato de magnésio $\left(\mathrm{MgSO}_{4}\right) ; \mathrm{N}$ - Ácido bórico $\left(\mathrm{H}_{3} \mathrm{BO}_{3}\right) ; 0$ - Água de abastecimento; $\mathrm{P}$ - Cloreto de ferro + Ácido etilenodiaminotetracético $\left(\mathrm{FeCl}_{3}+\mathrm{EDTA}\right)$

Tabela 2. Quantidade dos ingredientes e dos nutrientes utilizados na formulação de $100 \mathrm{~L}$ das soluções nutritivas e seus custos

\begin{tabular}{|c|c|c|c|c|c|c|c|c|c|c|c|c|c|c|c|c|c|}
\hline \multirow{2}{*}{ Soluções } & \multicolumn{16}{|c|}{ Quantidade dos ingredientes (kg) } & \multirow{2}{*}{$\begin{array}{c}\text { Custo } \\
R \$ 100 L^{-1}\end{array}$} \\
\hline & A & B & C & D & $E$ & $F$ & G & $\mathrm{H}$ & I & $\mathrm{J}$ & K & $\mathbf{L}$ & M & $\mathbf{N}$ & 0 & $\mathbf{P}$ & \\
\hline S1 & - & - & - & $3 \times 10^{-3}$ & 0,05 & 0,12 & $5,2 \times 10^{-3}$ & - & $3 \times 10^{-3}$ & $1 \times 10^{-5}$ & $3,1 \times 10^{-5}$ & $2 \times 10^{-4}$ & 0,05 & $2,8 \times 10^{-4}$ & 99,77 & $1,5 \times 10^{-3}$ & 0,75 \\
\hline S2 & - & 10,0 & - & - & 0,46 & 1,06 & 0,025 & - & - & - & - & - & 0,44 & - & 88,01 & - & 4,07 \\
\hline S3 & 0,13 & 16,0 & - & - & 0,44 & 1,02 & 0,010 & - & - & - & - & - & 0,39 & - & 82,01 & - & 3,89 \\
\hline \multirow[t]{3}{*}{ S4 } & 0,96 & 22,0 & - & - & 0,38 & 0,98 & - & - & - & - & - & - & 0,33 & - & 75,35 & - & 3,70 \\
\hline & \multicolumn{17}{|c|}{ Quantidade de nutrientes (kg) } \\
\hline & \multicolumn{2}{|c|}{$\mathbf{N}$} & \multicolumn{2}{|c|}{$\mathrm{P}_{2} \mathrm{O}_{5}$} & \multicolumn{2}{|l|}{$\mathrm{K}_{2} \mathrm{O}$} & $\mathrm{Ca}$ & \multicolumn{2}{|c|}{ Mg } & $S$ & \multicolumn{2}{|c|}{ B } & $\mathrm{Zn}$ & \multicolumn{2}{|c|}{$\mathrm{Fe}$} & Mn & $\mathrm{Cu}$ \\
\hline S1 & \multicolumn{2}{|c|}{$2,1 \times 10^{-2}$} & \multicolumn{2}{|c|}{$3 \times 10^{-3}$} & \multicolumn{2}{|c|}{$2,3 \times 10^{-2}$} & $2 \times 10^{-2}$ & \multicolumn{2}{|c|}{$5 \times 10^{-3}$} & $6,3 \times 10^{-3}$ & \multicolumn{2}{|c|}{$5 \times 10^{-5}$} & $1,1 \times 10^{-5}$ & \multicolumn{2}{|c|}{$5,02 \times 10^{-4}$} & $1 \times 10^{-4}$ & $2 \times 10^{-6}$ \\
\hline S2 & \multicolumn{2}{|c|}{0,21} & \multicolumn{2}{|c|}{0,031} & \multicolumn{2}{|c|}{0,234} & 0,203 & \multicolumn{2}{|c|}{0,048} & 0,105 & \multicolumn{2}{|c|}{-} & - & \multicolumn{2}{|c|}{-} & - & - \\
\hline S3 & \multirow{2}{*}{\multicolumn{2}{|c|}{$\begin{array}{l}0,21 \\
0,21\end{array}$}} & \multirow{2}{*}{\multicolumn{2}{|c|}{$\begin{array}{l}0,04 \\
0,04\end{array}$}} & \multicolumn{2}{|c|}{0,234} & 0,2 & \multirow{2}{*}{\multicolumn{2}{|c|}{$\begin{array}{l}0,048 \\
0.048\end{array}$}} & 0,131 & \multicolumn{2}{|l|}{ - } & - & \multicolumn{2}{|l|}{-} & - & - \\
\hline S4 & & & & & 0,234 & & 0,2 & & & 0,158 & - & & - & \multicolumn{2}{|l|}{ - } & - & - \\
\hline
\end{tabular}

A - Melaço; B - Biofertilizante; C - Soro de leite; D - Cloreto de potássio (KCI); E - Nitrato de potássio (KNO ); F - Nitrato de cálcio (Ca(NO); G - Fosfato monoamôneo (NH H.PO); H - Fosfato de potássio $\left(\mathrm{KH}_{2} \mathrm{PO}_{4}\right) ; \mathrm{I}$ - Cloreto de potássio $(\mathrm{KCl}) ; \mathrm{J}$ - Sulfato de cobre $\left(\mathrm{CuSO}_{4}\right) ; \mathrm{K}$ - Sulfato de zinco $\left(\mathrm{ZnSO}_{4}\right) ; \mathrm{L}$ - Sulfato de manganês $\left(\mathrm{MnSO}_{4}\right) ; \mathrm{M}^{-} \mathrm{Sulfato}$ de magnésio (MgSO $\left.{ }_{4}\right) ; \mathrm{N}$ - Ácido bórico $\left(\mathrm{H}_{3} \mathrm{BO}_{3}\right) ; 0$ - Água de abastecimento; P - Cloreto de ferro + ácido etilenodiaminotetracético (FeCl ${ }_{3}+$ EDTA); S1 - Solução mineral; S2 - Solução mineral + $10 \%$ de solução orgânica; S3 - Solução mineral + 16\% de solução orgânica e S4 - Solução mineral + 22\% de solução orgânica

O plantio da alface foi realizado acrescentando-se duas sementes pré-geminadas (em câmera BOD) em espuma de poliuretano com $3 \mathrm{~cm}$ de diâmetro e $2 \mathrm{~cm}$ de altura previamente enxaguada com água corrente com o objetivo de eliminar possíveis compostos ácidos remanescentes de sua fabricação. Durante os primeiros seis dias as espumas foram umedecidas apenas com água de abastecimento; nos $7^{\circ}, 13^{\circ}$ e $19^{\circ}$ dias acrescentaram-se as soluções S1, S2, S3 e S4 de modo que elas apresentassem, respectivamente, 33,33; 66,66 e 100\% da concentração nutricional sugerida por Hogland \& Snyder (1933); neste último período foram adicionadas, para $1000 \mathrm{~mL}$ de solução, as seguintes soluções estoque: 7,0 mL de S1; 8,0 mL de S2; 8,0 mL de S3 e 6,0 mL de S4; ao final de cada reposição se realizavam medições do potencial hidrogeniônico $(\mathrm{pH})$ e da condutividade elétrica (CE) da solução.

O sistema hidropônico utilizado foi o floating sem aeração; para isto, utilizaram-se recipientes plásticos com capacidade de $1 \mathrm{dm}^{3}$ previamente revestidos com papel alumínio para evitar a formação e a proliferação de algas; com a mesma intenção as tampas dos recipientes foram pintadas com tinta acrílica cromada.

O manejo da solução nutritiva foi realizado diariamente através da reposição da água consumida, do acompanhamento da condutividade elétrica (CE) e do potencial hidrogeniônico $(\mathrm{pH})$ mantendo-o próximo à neutralidade, com a utilização de uma solução de $\mathrm{NaOH}$ ou HCL $\left(1 \mathrm{~mol} \mathrm{~L}^{-1}\right)$. Objetivando facilitar a manutenção do pH e da CE obtiveram-se curvas de

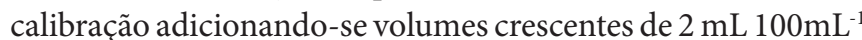
das soluções estoque. Os resultados obtidos foram submetidos à regressão polinomial adotando-se como critério para a escolha do melhor modelo, o coeficiente de determinação. O volume das soluções estoque adicionado ao $19^{\circ}$ dia, foi determinado com base nas equações das regressões tomando-se como referência uma CE de 1,75 dS $\mathrm{m}^{-1} \pm 0,05$ (Figura 1).

Após 25 dias da germinação das mudas procedeu-se à determinação das seguintes características de crescimento: altura da planta (ALT), determinada com uma régua graduada medindo-se o comprimento $(\mathrm{cm})$ entre o colo da planta e a parte superior da maior folha; diâmetro caulinar (DIA), determinado com um paquímetro medindo-se a distância entre as margens opostas do disco foliar (cm); número de folhas (NF), determinado pela contagem de folhas verdes maiores que 2,0 $\mathrm{cm}$ de comprimento; comprimento da raiz (CR), determinado com a utilização de régua graduada $(\mathrm{cm})$; massa da matéria fresca das folhas (MMF), estimada por pesagem em balança digital de precisão (g) e massa da matéria seca das folhas (MMS) 

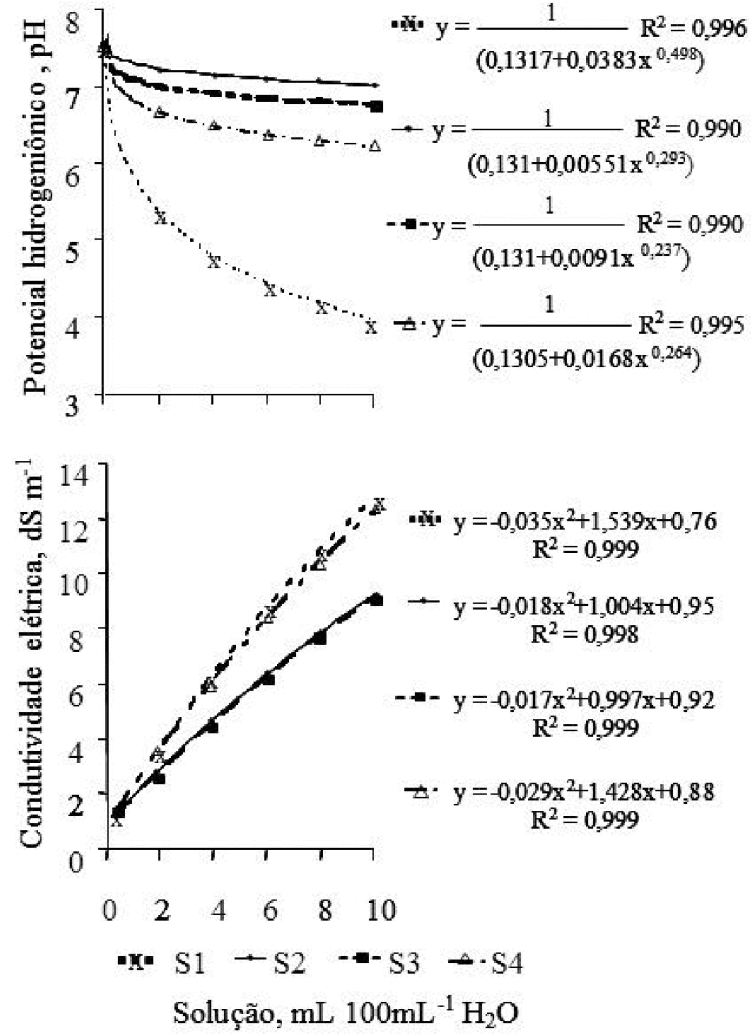

S1 - Solução mineral; S2 - Solução mineral + 10\% de biofertilizante supermagro; S3 - Solução mineral $+16 \%$ de biofertilizante supermagro e S4 - Solução mineral $+22 \%$ de biofertilizante supermagro

Figura 1. Curva de calibração do potencial hidrogeniônico e da condutividade elétrica em função das diferentes soluções nutritivas

determinada pelo peso seco obtido em estufa com circulação forçada de ar a $70^{\circ} \mathrm{C}$ até atingir peso constante (g).

Os dados coletados foram submetidos à análise da variância (teste F) e as médias comparadas pelo teste de Tukey a 0,05 de probabilidade utilizando-se o programa SISVAR 5.0 (Ferreira, 2000). Para efeito de análise estatística os dados das variáveis massa da matéria fresca e massa da matéria seca foram transformados em $\sqrt{ } \mathrm{x}+0,5$.

\section{Resultados e Discussão}

$\mathrm{Na}$ formulação das soluções S2, S3 e S4 não foi necessário acrescentar fertilizantes minerais fornecedores de micronutrientes visto que os ingredientes orgânicos utilizados supriram as exigências da cultura. Analisando a Figura 2 verifica-se, independente da solução nutritiva utilizada, que não foi constatada carência e/ou toxidez visual de nenhum nutriente.

Nas soluções S3 e S4 o nutriente fósforo, e nas soluções S2, S3 e S4 o enxofre calculado pela ferramenta Solver, após concentrados (10 vezes), foram disponibilizados em concentrações superiores às recomendadas por Hogland \& Snyder (1933) sem, contudo, provocar injúrias à alface. O excesso de fósforo pode causar deficiência de zinco e o enxofre pode ocasionar necrose internerval em algumas espécies de plantas (Rios, 2008).
C1
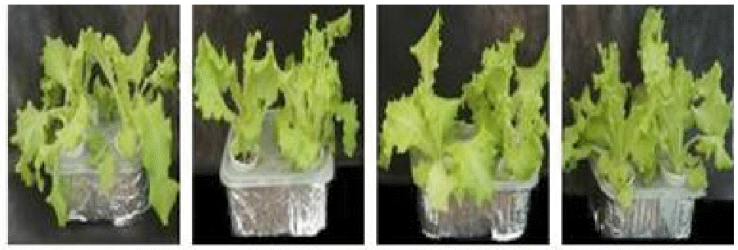

$\mathrm{C} 2$
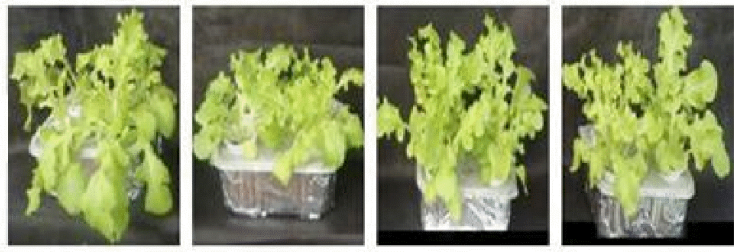

C3

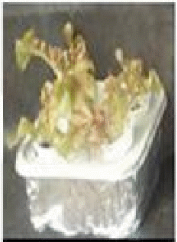

S1

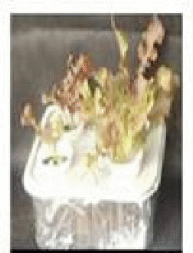

$\mathrm{S} 2$

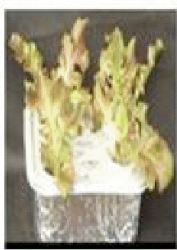

S3

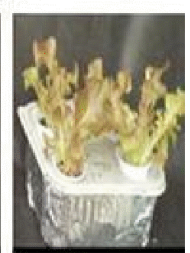

S4
S1 - Solução mineral; S2 - Solução mineral + 10\% de biofertilizante supermagro; S3 - Solução mineral $+16 \%$ de biofertilizante supermagro e S4 - Solução mineral $+22 \%$ de biofertilizante supermagro; C1 - Crespa; C2 - manteiga e C3 - Rubi

Figura 2. Respostas qualitativas de plantas de alface após 31 dias de cultivo

O ferro é absorvido preferencialmente na forma bivalente $\left(\mathrm{Fe}^{+2}\right)$ ao invés da trivalente $\left(\mathrm{Fe}^{+3}\right)$; seu transporte no xilema se dá como Fe-quelatado e a deficiência deste nutriente é caracterizada pela clorose das folhas e, em casos mais avançados, pode ocorrer amarelecimento total seguido de necrose nos bordos do limbo e, em consequência, desfolha total da planta. As plantas de alface cultivadas com as soluções organominerais não apresentaram deficiência visual de Fe (Figura 2) mesmo sem apresentar cloreto de ferro mais EDTA (quelatante) na sua constituição; este elemento foi fornecido às plantas provavelmente complexado a compostos orgânicos tais como: álcoois, ésteres, diquetonas e aldeídos (Moruzzi \& Reali, 2012).

Observa-se, na Figura 3, que no início do experimento o $\mathrm{pH}$ da solução apresentava valor 7,66 , visto que a mesma era constituída apenas com água de abastecimento proveniente da Companhia de Água e Esgotos da Paraíba - CAGEPA, município de Campina Grande, $\mathrm{PB}$, a qual apresenta dureza moderada (50 a $\left.150 \mathrm{mg} \mathrm{CaCO} \mathrm{L}^{-1}\right)$. Para se evitar estresse salino Castellane \& Araújo (1994) não recomendam o uso de soluções nutritivas concentradas nos primeiros dias após a germinação.

Independente das cultivares verifica-se, aos $7^{\circ}, 13^{\circ}$ e $19^{\circ}$ dias após a germinação, redução nos valores do $\mathrm{pH}$ em todas as soluções nutritivas, comportamento esperado já que ocorreram, nesses períodos, as reposições com soluções estoque cujo $\mathrm{pH}$ era ácido; desta forma, a redução no $\mathrm{pH}$ é consequência do aumento nas concentrações dos nutrientes confirmando os resultados obtidos com as curvas de calibração (Figura 1). Nas soluções S2, S3 e S4 a redução no $\mathrm{pH}$ foi consequência da aplicação de $1 \mathrm{~mol} \mathrm{~L}^{-1}$ de $\mathrm{HCl}$, aos 22 dias. Segundo Gomes et al. (2011), o pH proporciona efeito indireto na solubilidade dos nutrientes; em valores elevados poderá ocorrer formação 

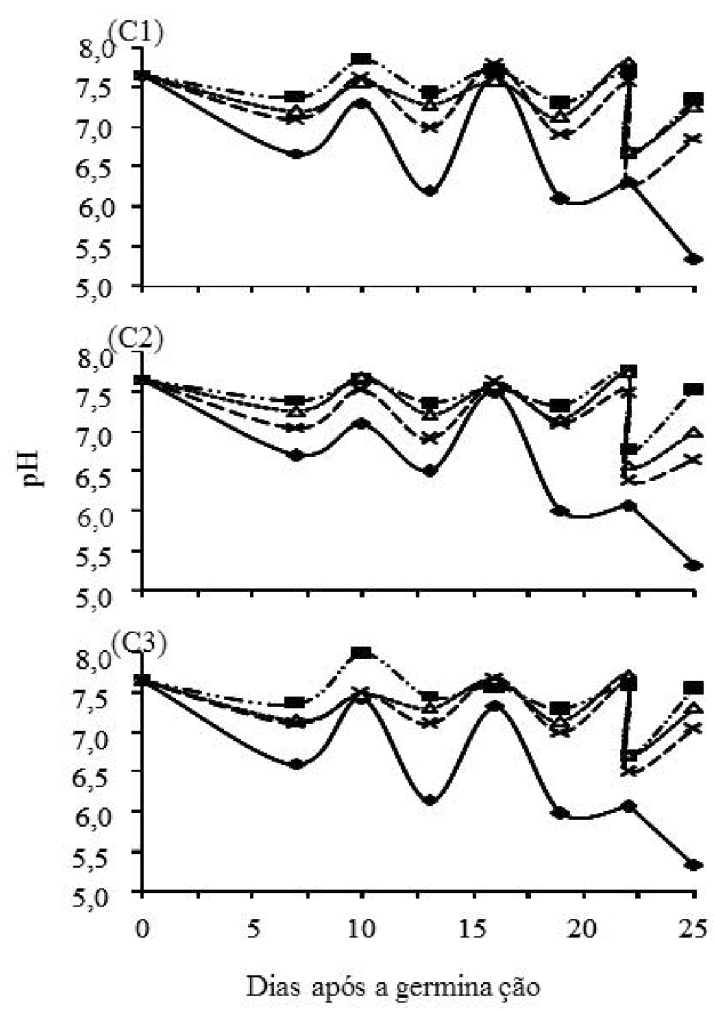

$\rightarrow \mathrm{S} 1 \rightarrow \mathrm{S} 2 \stackrel{\mathrm{S} 3}{\mathrm{~S}} \stackrel{\mathrm{S} 4}{\mathrm{~S}}$

Figura 3. Curva de calibração do potencial hidrogeniônico $(\mathrm{pH})$ em função das diferentes soluções nutritivas (S1 = solução mineral; S2 - Solução mineral $+10 \%$ de solução orgânica; S3 - Solução mineral $+16 \%$ de solução orgânica e S4 - Solução mineral $+22 \%$ de solução orgânica) e cultivares (C1 - Crespa; C2 - Manteiga e C3 - Rubi) durante a condução do experimento

de precipitados de alguns elementos, tais como: cálcio, fósforo, ferro e manganês, que deixam de estar disponíveis às plantas.

Analisando a Figura 3 percebe-se ainda, em relação à solução mineral S1, um poder tamponante maior das soluções S2, S3 e S4 cuja variação foi, durante a condução do experimento, de 7,7 a 6,6 contra 7,7 a 5,3 da solução mineral. É certo que substâncias húmicas e fúlvicas exercem poder tampão sobre o $\mathrm{pH}$ do solo (Dobbss et al., 2008) porém, quanto às soluções nutritivas utilizadas em sistema hidropônico, pouco se sabe. Os resultados obtidos com este trabalho são promissores considerando-se que a manutenção do $\mathrm{pH}$ é uma das operações mais trabalhosas quando se conduzem experimentos com soluções nutritivas pois como as mesmas não apresentam capacidade tampão, sua acidez ou alcalinidade necessita ser diariamente ajustada para uma faixa de $\mathrm{pH}$ adequada, através da adição de uma solução básica ou ácida, respectivamente (Braccini et al., 1999). Segundo Fonseca et al. (2005), a utilização de agentes tamponantes é importante tanto para a pesquisa quanto para os agricultores, por aperfeiçoar operações de correção do pH das soluções nutritivas.

Aos 10,16 e 22 dias após a germinação verificou-se, independente da cultivar, uma elevação no valor do $\mathrm{pH}$, o que pode estar associado à forma com que o nitrogênio é disponibilizado à planta haja vista que absorções aniônicas, a exemplo do íon nitrato $\left(\mathrm{NO}_{3}^{-}\right)$, proporcionam aumento no $\mathrm{pH}$ através da liberação de bicarbonatos $\left(\mathrm{HCO}_{3}^{-}\right)$ou hidroxilas $\left(\mathrm{OH}^{-}\right)$pelas raízes e o oposto ocorre se cátions, tais como o íon amônio $\left(\mathrm{NH}_{4}^{+}\right)$são absorvidos mais rapidamente do que ânions, havendo liberação de íons hidrogênio $\left(\mathrm{H}^{+}\right)$ (Braccini et al., 1999). Após a última calibração (22 dias), verificaram-se acréscimos no valor do $\mathrm{pH}$, com a utilização das soluções S2, S3 e S4, o mesmo não se constatando com a solução mineral $\mathrm{S} 1$.

Quanto à condutividade elétrica (CE), a reposição das soluções nutritivas aos $7^{\circ}, 13^{\circ}$ e $19^{\circ}$ dias após a germinação proporcionou aumento deste parâmetro, independente da cultivar, cujos valores variaram entre $0,67 \mathrm{dS} \mathrm{m}^{-1}$ a valores próximos de 1,6 $\mathrm{dS} \mathrm{m}^{-1}$ (Figura 4).

O acréscimo da condutividade elétrica seguiu as recomendações de Cometti (2003), ou seja, de que não se utilize até os 31 dias após a semeadura, uma solução com concentração inferior a $50 \%$ da força iônica; caso contrário, poderá haver redução no crescimento inicial da alface.

Durante os períodos compreendidos entre 7-10, 13-16 e 19-25 dias após a germinação ocorreu diminuição gradual da $\mathrm{CE}$ em virtude da absorção de nutrientes. Corroborando com
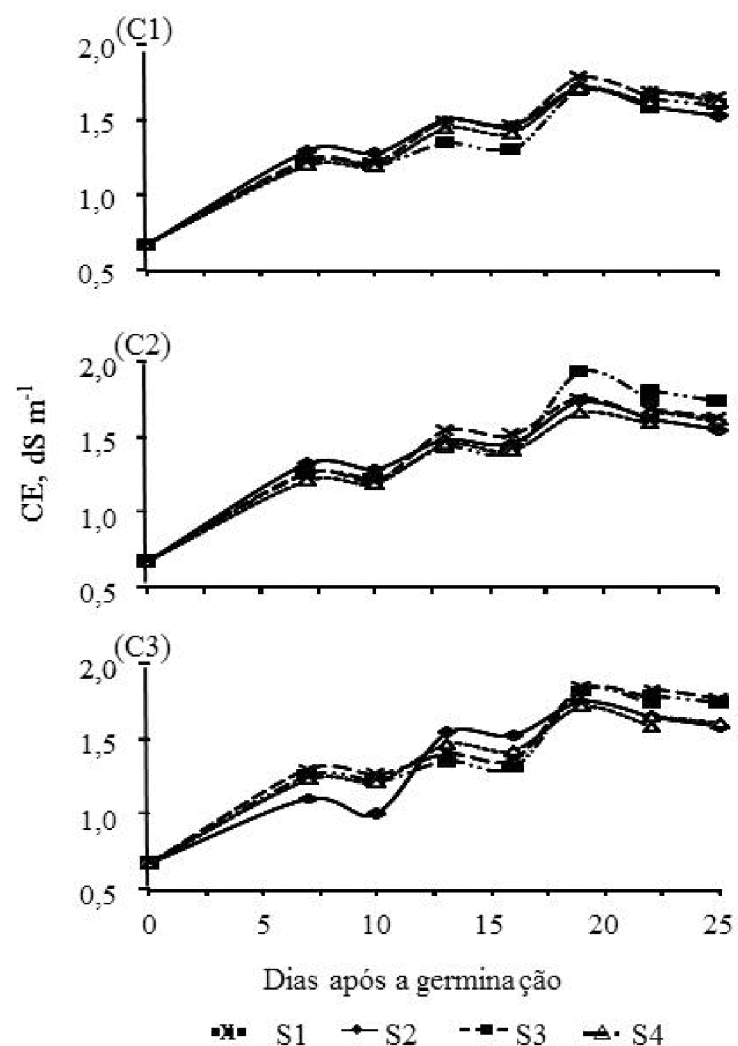

Figura 4. Curva de calibração da condutividade elétrica (CE) em função das diferentes soluções nutritivas (S1 - Solução mineral; S2 - Solução mineral + $10 \%$ de solução orgânica; S3 - Solução mineral + $16 \%$ de solução orgânica e S4 - Solução mineral + $22 \%$ de solução orgânica) e cultivares (C1 - Crespa; C2 - Manteiga e C3 - Rubi) durante a condução do experimento 
esta observação Backes et al. (2004) verificaram resultados semelhantes. Os maiores decréscimos no valor da condutividade elétrica só foram observados após o $19^{\circ}$ dia, isto porque a partir dos 21 dias após transplantio, ocorre um acúmulo maior de matéria seca na planta decorrente da maior absorção de nutrientes e, em contrapartida, diminuição da CE da solução nutritiva (Beninni et al., 2005).

De maneira geral, a variação da condutividade elétrica em todos os tratamentos esteve dentro do recomendado por (Resh, 1997) uma vez que aos 19 dias após a germinação os valores ocilaram entre 1,5 e 2,0 dS m $\mathrm{m}^{-1}$, considerados adequados para o cultivo da alface em sistema hidropônico.

Os resultados da análise de variância (Tabela 3) indicaram que as variáveis altura da planta (ALT) e diâmetro caulinar (DIA) foram influenciados significativamente pela interação solução versus cultivar. O crescimento da raiz (CR) diferiu com a utilização das soluções e as variáveis massa da matéria fresca (MMF) e massa da matéria seca (MMS) diferiram estatisticamente entre soluções e cultivares.

Independente das cultivares, a altura de planta não diferiu estatisticamente entre as diferentes soluções mas se percebe, avaliando a influência das soluções sobre as cultivares, que a Crespa (C1) e a Manteiga (C2) submetidas a solução mineral apresentaram crescimento superior quando comparadas com a Rubi (C3). Com a utilização da solução S2 as cultivares Manteiga e Crespa apresentaram as maiores médias; contudo, esta última também não diferiu da Rubi (C3). A altura das cultivares foi a mesma apenas com a utilização das soluções S3 e S4 (Figura 5A).

Quanto ao diâmetro caulinar observa-se, apenas com a utilização da cultivar Rubi (C3), diferença significativa entre soluções cujas maiores médias foram obtidas utilizando-se S1 e S3 e as menores médias com o uso da S2 e S4, porém sem diferirem estatisticamente da S1. Ainda comparando essa cultivar com as demais conclui-se que os melhores resultados foram obtidos mais uma vez com o uso das soluções S1 e S3 (Figura 5B). As menores médias verificadas com a cultivar Rubi estão em consonância com os resultados obtidos por Nodari et al. (2011) que, trabalhando com diversas cultivares (Lavinia, Melissa, Rubi, Green Salad Bowl e Mimosa) constataram que as menores produtividades foram obtidas com a cultivar Rubi.

Em ordem decrescente os maiores comprimentos de raízes foram verificados com a utilização das soluções: $\mathrm{S} 1>\mathrm{S} 4 \geq$ S3 $\geq$ S2 (Figura 6). Em média, os $16,5 \mathrm{~cm}$ de comprimento
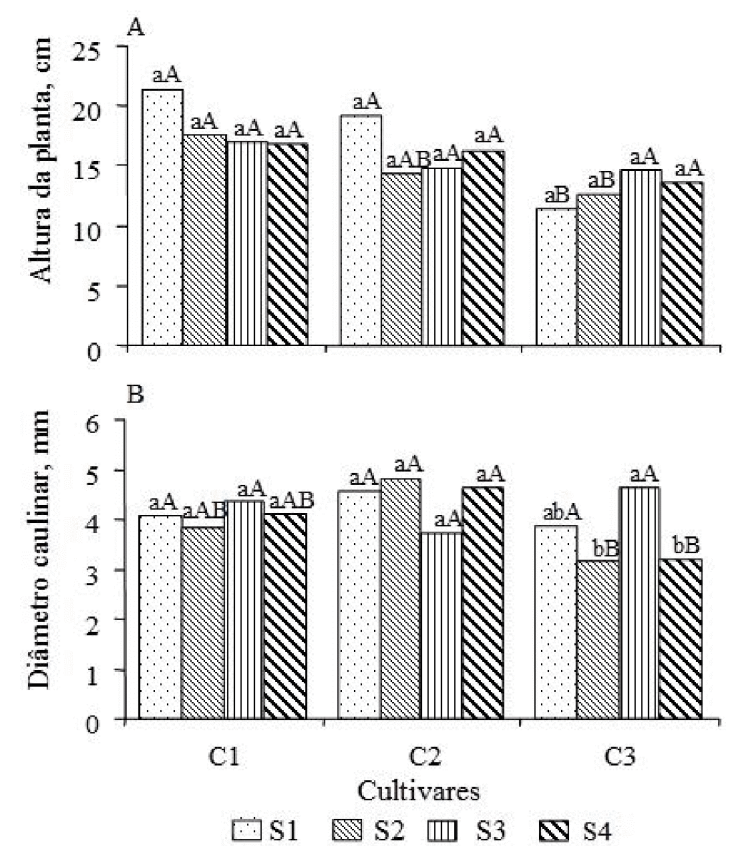

Letras minúsculas iguais indicam que as soluções não diferem estatisticamente entre si dentro da mesma cultivar, letras maiúsculas iguais indicam que cultivares não diferem entre si dentro da mesma solução

Figura 5. Altura da planta (A) e diâmetro caulinar (B) em função do desdobramento entre soluções nutritivas (S1 = solução mineral; S2 - Solução mineral + 10\% de solução orgânica; S3 - Solução mineral + 16\% de solução orgânica e S4 - Solução mineral + $22 \%$ de solução orgânica) e cultivares (C1 - Crespa; C2 Manteiga e C3 - Rubi)

radicular obtido com a utilização da solução mineral (S1) se assemelham com os $18,09 \mathrm{~cm}$ verificados por Maluf et al. (2011) aos 30 dias após o plantio e cultivadas em sistema floating. De acordo com Filgueira (2005), o enraizamento e o reinício do desenvolvimento da planta após o estresse do transplante são favorecidos quando as mudas possuem raízes maiores e tecidos ricos em matéria seca.

A menor média obtida com a utilização das soluções organominerais, em especial a $90 \%$ de solução mineral + 10\% de solução orgânica (S2), está associada à falta de oxigênio nas soluções nutritivas o que promoveu o escurecimento das raízes. A fase crítica foi observada após a segunda reposição, no $13^{\circ}$ dia, ocasião em que as soluções exalaram odor desagradável; durante este período também foram registrados os maiores valores de temperatura no interior da casa de vegetação $(>30$ $\left.{ }^{\circ} \mathrm{C}\right)$. Chérif et al. (1997) e Sutton et al. (2006) confirmam a

Tabela 3. Análise de variância para altura da planta (ALT), diâmetro caulinar (DIA), número de folhas (NF), comprimento da raiz (CR), peso da matéria fresca (MMF) e peso da matéria seca (MMS)

\begin{tabular}{|c|c|c|c|c|c|c|c|}
\hline \multirow{2}{*}{ Fator de variância } & \multirow{2}{*}{ G.L. } & \multicolumn{6}{|c|}{ Quadrado médio } \\
\hline & & ALT & DIA & NF & CR & $\operatorname{MMF}^{(1)}$ & MMS $^{(1)}$ \\
\hline Solução (S) & 3 & $9,64^{\text {ns }}$ & $0,19^{\text {ns }}$ & $0,70^{\text {ns }}$ & $86,23^{\star \star}$ & $0,27^{*}$ & $0,004^{*}$ \\
\hline Cultivar (C) & 2 & $79,51^{\star *}$ & $1,54^{*}$ & $1,33^{\text {ns }}$ & $0,83^{\text {ns }}$ & $0,37^{\star}$ & $0,012^{\star \star}$ \\
\hline $\mathrm{C} \times \mathrm{S}$ & 6 & $11,68^{*}$ & $1,02^{*}$ & $0,14^{\mathrm{ns}}$ & $7,45^{\text {ns }}$ & $0,027^{\mathrm{ns}}$ & $0,001^{\text {ns }}$ \\
\hline Resíduo & 25 & 4,43 & 0,39 & 0,88 & 4,21 & 0,07 & 0,0011 \\
\hline CV (\%) & & 13,30 & 15,39 & 16,16 & 16,62 & 12,89 & 3,24 \\
\hline
\end{tabular}

(1)Dados transformados $\sqrt{ } \mathrm{x}+1$ 


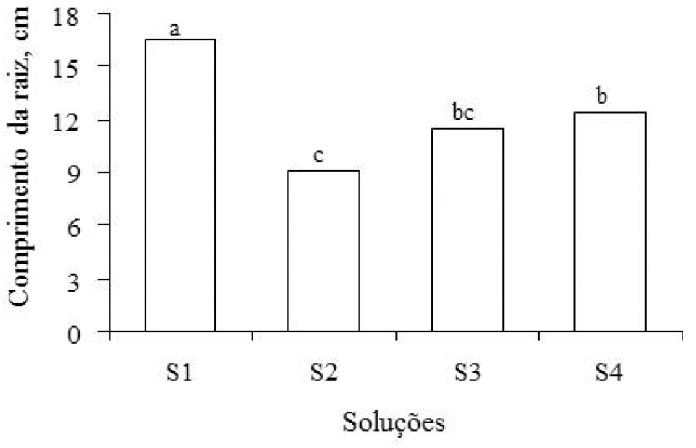

S1 - Solução mineral; S2 - Solução mineral + 10\% de solução orgânica; S3 - Solução mineral + 16\% de solução orgânica e S4 - Solução mineral + 22\% de solução orgânica

Figura 6. Comprimento da raiz em função das diferentes soluções nutritivas

influência do oxigênio (hipoxia) e de temperaturas elevadas sobre o escurecimento das raízes.

Após a terceira reposição $\left(19^{\circ}\right.$ dia $)$ e independente da cultivar utilizada, observaram-se emissões de novas radículas em todas as soluções organominerais e, em contrapartida, aumento na absorção de nutrientes. Em média, ao final dos últimos seis dias de avaliação o volume de água evapotranspirado foi de 266,6 (S1), 291,6 (S2), 269,0 (S3) e 416,6 mL (S4) para a cultivar Crespa; 333,3 (S1), 216,6 (S2), 335,0 (S3) e 400 mL (S4) para a cultivar Manteiga e 233,3 (S1), 283,3 (S2), 300 (S3) e $206 \mathrm{~mL}$ (S4) para a cultivar Rubi.

O resultado das variáveis altura de planta e diâmetro caulinar, anteriormente discutido, evidencia que a influência negativa sobre o comprimento das raízes foi devida à falta de oxigenação e não de carência ou toxidez nutricional das soluções organominerais.

Em termos de produção a massa da matéria fresca é a variável mais importante pois apresenta relação com a altura da planta e com o aspecto comercial. A substituição de 16\% da solução mineral pela orgânica promoveu a menor produção de matéria fresca; apesar disto, sem diferir estatisticamente das soluções S2 e S4 (Figura 7A). Quanto às cultivares, a produção de massa fresca reforça o que já foi discutido, ou seja, que a cultivar Rubi apresenta menor crescimento em relação à Crespa (C1) e à Manteiga (C2).

Mesmo constatando o escurecimento das raízes, principalmente com a solução $S 2$, as médias obtidas para massa fresca das folhas evidenciam que as soluções organominerais S2, S3 e S4 se encontram nutricionalmente balanceadas. Tais resultados corroboram com os encontrados por Ribeiro et al. (2007) que não verificaram diferença significativa para massa fresca de folhas quando utilizaram solução mineral e solução mineral acrescidas com até $60 \%$ de biofertilizante. Embora o baixo teor de nutrientes na solução do biofertilizante tenha ocasionado redução no desenvolvimento da alface, Costa et al. (2006) encontraram interações positivas com o uso de biofertilizantes na produção de duas cultivares de alface sobre a fitomassa fresca da parte aérea e o número de folhas da cultivar Babá de verão.

De acordo com Cometti et al. (2008) resultados relacionados à massa fresca das folhas são importantes uma vez que muitos produtores hidropônicos vêm oferecendo o produto
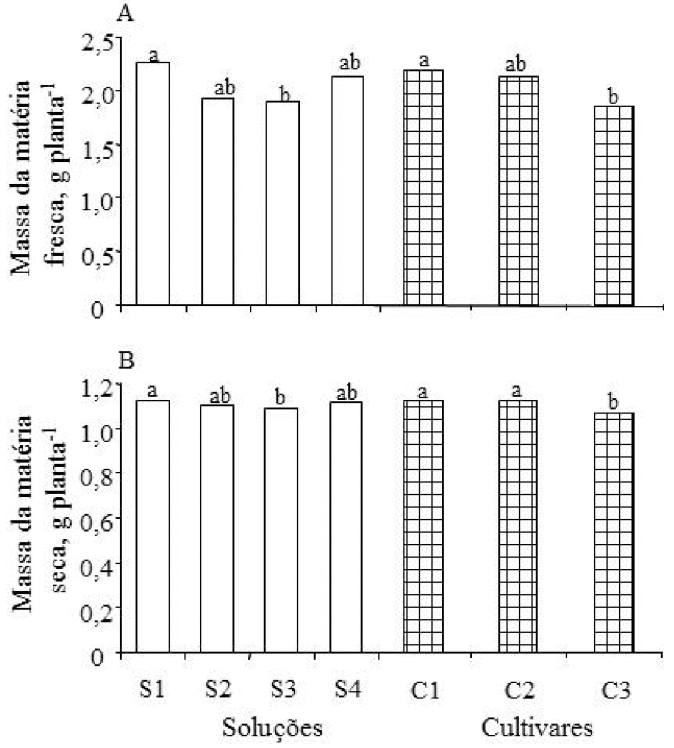

Dados transformados $\sqrt{ } x+1$, Letras minúsculas iguais indicam que as soluções não diferem estatisticamente entre si dentro da mesma cultivar, letras maiúsculas iguais indicam que cultivares não diferem entre si dentro da mesma solução

Figura 7. Massa da matéria fresca (A) e seca (B) das folhas em função das diferentes soluções nutritivas (S1 - Solução mineral; S2 - Solução mineral + 10\% de solução orgânica; S3 - Solução mineral + 16\% de solução orgânica e S4 - Solução mineral + 22\% de solução orgânica) e cultivares (C1 - Crespa; C2 Manteiga e C3 - Rubi) aos 25 dias após a germinação

minimamente processado, na forma de folhas destacadas, lavadas e embaladas em bandejas, de maneira que o mais relevante não é mais a produção da "cabeça" de alface mas, sim, a massa de folhas pela qual as embalagens são padronizadas.

A massa da matéria seca (Figura 7B) apresentou resultado semelhante ao da massa da matéria fresca contradizendo as informações de Dias et al. (2009) que verificaram redução significativa da massa seca da parte aérea com a substituição de $25 \%$ de solução mineral por biofertilizante.

\section{Conclusões}

1. Independente da solução nutritiva não foram verificadas carência nem toxidez visual na alface; assim, é possível substituir parcialmente a solução mineral por soluções organominerais desde que a solução final se encontre nutricionalmente adequada.

2. As soluções organominerais promoveram maior resistência à variação do $\mathrm{pH}$ durante a condução do experimento porém houve, após cada reposição, a necessidade de correção do $\mathrm{pH}$ para valores próximos de 7,0, antes de serem utilizadas no sistema hidropônico.

3. As soluções mineral e mineral $+10 \%$ de solução orgânica promoveram as maiores alturas nas cultivares Crespa e Manteiga. O maior comprimento da raiz foi observado com a utilização da solução mineral e as menores médias de matéria fresca e seca foram obtidas com o uso da solução mineral + $16 \%$ de solução orgânica e da cultivar Rubi. 


\section{Literatura Citada}

Backes, F. A. A. L.; Santos, O. S.; Pilau, F. G.; Bonnecarrère, R. A. G.; Medeiros, S. L. P.; Fagan, E. B. Reposição de nutrientes em solução nutritiva para o cultivo hidropônico de alface. Ciência Rural, v.34, p.1407-1414, 2004.

Beninni, E. R. Y.; Takahashi, H. W.; Neves, C. S. V. J. Concentração e acúmulo de macronutrientes em alface cultivada em sistemas hidropônico e convencional. Semina: Ciências Agrárias, v.26, p.273-282, 2005.

Braccini, M. C. L.; Braccini, A. L. E.; Martinez, H. E. P. Critérios para renovação ou manutenção de solução nutritiva em cultivo hidropônico. Ciências Agrárias, v.20, p.48-57, 1999.

Castellane, P. D.; Araújo, J. C. Cultivo sem solo - Hidroponia. SOB Informa, v.13, p.28-29, 1994.

Chérif, M.; Tirilly, Y.; Bélanger, R. R. Effect of oxygen concentration on plant growth, lipid peroxidation, and receptivity of tomato roots to Pythium F under hydroponic conditions. European Journal of Plant Pathology, v.103, p.255-264, 1997.

Cometti, N. N. Nutrição mineral da alface (Lactuca sativa L.) em cultura hidropônica - Sistema NFT. Seropédica: UFRRJ, 2003. 106p. Tese Ph.D

Cometti, N. N.; Matias, G. C. S; Zonta, E; Mary, W; Fernandes, M. S. Efeito da concentração da solução nutritiva no crescimento da alface em cultivo hidropônico - Sistema NFT. Horticultura Brasileira, v.26, p.252-257, 2008.

Costa, N. E.; Ribeiro, M. C. C.; Lima, J. S. S.; Cardoso, A. A.; Oliveira, G. L. Utilização de biofertilizante na alface para o sistema hidropônico floating. Revista Verde de Agroecologia e Desenvolvimento Sustentável, v.1, p.41-47, 2006.

Dias, N. S.; Brito, A. A. F.; Sousa Neto, O. N.; Lira, R. B.; Brito, R. F. Produção de alface hidropônica utilizando biofertilizante como solução nutritiva. Revista Caatinga, v.22, p.158-162, 2009.

Dobbss, L. B.; Canellas, L. P.; Alleoni, L. R. F.; Rezende, C. E.; Fontes, M. P. F.; Velloso, A. C. X. Eletroquímica de latossolos brasileiros após a remoção da matéria orgânica humificada solúvel. Revista Brasileira de Ciência do Solo, v.32, p.985-996, 2008.

Factor, T. L.; Araujo, J. A. C.; Vilella Junior, L. V. E. Produção de pimentão em substratos e fertirrigação com efluente de biodigestor. Revista Brasileira de Engenharia Agrícola e Ambiental, v.12, p.143-149, 2008.

Fernandes J. D.; Monteiro Filho A. F.; Chaves L. H. G.; Gonçalves C.; P. Cruz M. P. Formulação de biofertilizante utilizando a ferramenta Solver do Microsoft Office. Revista Verde de Agroecologia e Desenvolvimento Sustentável, v.6, p.101-105, 2011.

Ferreira, D. F. Análise estatística por meio do SISVAR (Sistema para Análise de Variância) para Windows versão 4.0. In: Reunião Anual da Região Brasileira da Sociedade Internacional de Biometria, 45. São Carlos, 2000. Anais... São Carlos, UFSCar, 2000. p.255-258. CD- Rom

Filgueira, F. A. R. Novo manual de olericultura: Agrotecnologia moderna na produção e comercialização de hortaliças. 2.ed. Viçosa: UFV. 2005. 412p.

Fonseca, M. C. M.; Raslan, K. R.; Martinez, H. E. P.; Pereira, P. R. G.; Barbosa, J. G. Tamponamento do $\mathrm{pH}$ da solução nutritiva na hidroponia de plantas ornamentais. Revista Brasileira de Horticultura Ornamental, v.11, p.100-108, 2005.
Gomes, L. S.; Martins, C. A. S.; Nogueira, N. O.; Lopes,F. S.; Xavier, T. M. T.; Cardoso, L. C. M. Efeito de diferentes valores de $\mathrm{pH}$ da solução nutritiva no desenvolvimento de variedades de melão. Revista Brasileira de Ciências Agrárias, v.6, p.73-78, 2011.

Hoagland, D. R.; Snyder, W. C. Nutrition of strawberry plants under controlled conditions: (A) Effects of deficiencies of boron and certain other elements: (B) Susceptibility to injury from sodium salts. Proceedings of the American Society of Horticultural Science, v.30, p.288-294, 1933.

Maluf, G. E. G. M.; Paula, A. C. C. F. F.; Leite, P. C.; Alvarenga, A. A.; Maluf, H. J. G. M. Efeito da iluminação noturna complementar a $18 \mathrm{~cm}$ de altura no crescimento de mudas de alface (Lactuca sativa L.). In: Semana de Ciência e Tecnologia do IFMG, 6, 2011, Jornada Científica, 4, 2011, Bambuí. Anais...Bambuí: Instituto Federal de Educação, Ciência e Tecnologia, 2011. CD-Rom

Martello, L. S.; Marcatti, B.; Moretti, T. S.; Petrus, R. R.; Almeida, E.; Ferraz, J. B. S. Efeito dos sistemas de cultivo orgânico, hidropônico e convencional na qualidade de alface lisa. Brazilian Journal of Food Technology, v.10, p.111-115, 2007.

Moruzzi, R. B.; Reali, M. A. P. Oxidação e remoção de ferro e manganês em águas para fins de abastecimento público ou industrial - Uma abordagem geral. Revista de Engenharia e Tecnologia, v.4, p.29-43, 2012.

Nodari, I. D. E.; Junior, S. S.; Diamante, M. S.; Dias, L. D. E.; Neves, J. F. Desempenho de cultivares de alface tipo mimosa sob altas temperaturas em Cáceres MT. In: Congresso de Iniciação Científica, 4, 2011, Cáceres. Anais... Cáceres: Universidade do Estado de Mato Grosso, 2011. CD-Rom

Pereira, L. G. R.; Araújo, G. G. L.; Voltolini, T. V.; Barreiros, D. C. Manejo nutricional de ovinos e caprinos em regiões semiáridas. In: Seminário Nordestino de Pecuária, 11, 2007, Fortaleza. Repensando o agronegócio da pecuária: Novos caminhos. Anais...Fortaleza: FAEC; CNA; SENAR; SEBRAECE, 2007. CD- Rom

Resh, H. Hydroponic food productions. 5.ed. Califórnia: Woodbridge Press Publishing Company, 1997. 527p.

Ribeiro, K. S.; Ferreira, E.; Costa, M. S. S. M.; Gazola, D.; Szimanski, C. Uso de biofertilizante no cultivo de alface hidropônica. Revista Brasileira de Agroecologia, v.2, p.160164, 2007.

Rios, E. C. S. V. Uso de águas amarelas como fonte alternativa de nutriente em cultivo hidropônico da alface (Lactuca sativa). Vitória: UFES, 2008. 85p. Dissertação Mestrado

Santos, D.; Mendonça, R. M. N.; Silva, S. M.; Espínola, J. E. F.; Souza, A. P. Produção comercial de cultivares de alface em Bananeiras. Horticultura Brasileira, v.29, p.609-612, 2011.

Silva, V. de P. R. da; Pereira, E. R. R.; Azevedo, P. V. de; Sousa, F. de A. S.; Sousa, I. F. Análise da pluviometria e dias chuvosos na região Nordeste do Brasil. Revista Brasileira de Engenharia Agrícola e Ambiental, v.15, p.131-138, 2011.

Sutton, J. C.; Sopher, C. R.; Owen-Going, T. N.; Liu, W.; Grodzinski, B.; Hall, J. C.; Benchimol, R. L. Etiology and epidemiology of Pythium root rot in hydroponic crops: Current knowledge and perspectives. Summa Phytopathology, v.32, p.307-321, 2006. 